\title{
The storytelling arms race: origin of human intelligence and the scientific mind
}

\author{
Enrico Coen $\mathbb{1}^{1}$
}

Received: 8 November 2018 / Revised: 27 January 2019 / Accepted: 29 January 2019

(c) The Genetics Society 2019

\begin{abstract}
Human language and intelligence go far beyond biological needs, allowing us to discuss abstract ideas, construct imaginary worlds, and do science and mathematics. How did such an ability arise? I propose that a major contributing factor was an arms race between truth and deception in storytelling. In honeybees, an elaborate language could evolve because reproductive conflicts of interest between individuals were reduced. For humans, however, reproductive conflicts of interest became a spur for increasing intelligence. Through the drive to negotiate social interactions, primate intelligence reached the point where knowledge could be shared through basic problem-resolution proto-stories, building on the way animals learn. As soon as honest proto-stories became possible, so did dishonest ones, ushering in an arms race between truth and deception, through which stories, language and skills in detecting lies through contradictions, were driven to ever greater heights. In telling stories to others, humans also told them to themselves, allowing them to think consciously and plan ahead. Through fictions they could share understanding by making discrepancies stronger and more engaging. Science arose when skills in detecting lies through empirical contradictions were applied to stories about how the world operates, whereas mathematics arose when skills in discerning lies through self-contradiction were applied to abstract reasoning. Both scientists and mathematicians used the storytelling structure of problem-chain-resolution to share their findings, founded on the principles of animal learning. Human intelligence thus arose through, and continues to depend upon, a balance between trust and doubt in the stories we share.
\end{abstract}

\section{Introduction}

Why do we tell stories? For the past few years I have posed this question to the $20 \mathrm{PhD}$ students and postdocs who attend the annual Science Communication course, run by the Genetics Society. The initial answers are usually positive. We tell stories to inform, to share, to educate, to engage; qualities that are also desirable for scientific papers and presentations. After this list has been exhausted, I ask the participants whether there might also be negative reasons for telling stories. A second list emerges: to deceive, to mislead, to conceal, to manipulate. These are aspects that should be avoided at all costs in scientific communication, prompting some to say that scientists should avoid telling

Enrico Coen

enrico.coen@jic.ac.uk

1 Department of Cell and Developmental Biology, John Innes Centre, Colney Lane, Norwich NR4 7UH, UK stories (Katz 2013). Stories are two-headed beasts that can be used to inform or deceive.

This conflict between truth and falsity is not specific to stories, however; it lies at the heart of the scientific method. Referees evaluate manuscripts by checking whether claims are likely to be valid or misleading. They search for inconsistencies or contradictions to make sure all is in order. Karl Popper has argued that the scientific method depends on falsification - taking hypotheses that we might think are true, trying to test or falsify them, and then coming up with better ones if necessary (Magee 2010; Popper 2002). Of course, proponents of scientific hypotheses do not intend to deceive; they aim to provide the best explanation given the available evidence. It is only later, through critical examination and testing, that hypotheses may be shown to be false. Someone who deceives with intent, by faking data, for example, would be considered a traitor to the scientific cause.

Science is only possible because scientists care deeply about truth and falsity. Where does this care come from? We might give a pragmatic answer: if scientists did not care 
about what was true or not, science would be full of errors and would therefore be of no practical use. Yet, practical considerations need not be at the forefront of a scientist's mind. Many scientists are driven by the urge to understand, to know how the world really works.

I would like to propose that the origins of human intelligence and the scientific mind are to be found in the twoheaded nature of stories, their ability to both inform and deceive. Numerous hypotheses have been proposed for the origin of human intelligence. Many emphasise the role of ecological challenges, such as developing tools (Gibson and Ingold 1993; Ko 2016; Wynn 1988), hunting (Hill 1982), scavenging (Blumenschine and Cavallo 1992), foraging (Kaplan et al. 2000), cooking (Wrangham et al. 1999), extended lifespans (Kaplan and Robson 2002) or variable environments (Potts 1998). Others emphasise the role of social interactions: maintaining social relations through gossip (Dunbar 2004); cognitive algorithms for social exchange (Cosmides et al. 2010; Cosmides and Tooby 2013); sexual selection for intelligence (Miller 2001; Rozsa 2008); an arms race based on social competition (Alexander 1990; Flinn et al. 2005). It is unclear, however, how any of these hypotheses account for our ability and drive to do science and mathematics. I suggest that a major factor in the evolution of human language and intelligence was an arms race between truth and deception in storytelling.

We often associate stories with escape from reality, the opposite of the scientific endeavour. So how can a central role for storytelling in science and intelligence be justified? A good place to begin is with the biological origins of honesty and deception.

\section{Honest and dishonest signalling}

A major problem in evolutionary biology is to understand what maintains the honesty or reliability of signals in the face of conflicts of interest. From an evolutionary perspective, a signal may be defined as an act or structure that alters the behaviour of other organisms, which evolved because of that effect, and which is effective because the receiver's response has also evolved (Smith and Harper 2003). Floral displays, for example, evolved to attract pollinators such as bees. The response of bees also evolved because they have come to rely on collecting pollen and nectar from flowers. There is a common interest for the signaller and receiver: the flowering plant gains by having pollen delivered, and the bee gains from the food provided by the flower.

There are cases, however, where the relationship of mutual benefit breaks down because of a conflict of interest. Snapdragons (Antirrhinum) have closed flowers that are pollinated by bees prising them open and entering to collect the nectar, held in a small pouch at the base of the flower. However, some bees are able to access the nectar directly by piercing a hole in the pouch, without entering the flower. Such behaviour is commonly referred to as "nectar robbing" because the bee benefits but the flower does not (Inouye 1983). A floral signal that was originally beneficial to both parties has become a cue, a one-sided indicator for the robber bee for where a free lunch is to be had. Onesidedness may also go in the other direction. Bee orchids attract pollinators by mimicking female insects, through appearance and production of pheromones, so that males attempt to copulate with them (Ayasse et al. 2003). During the attempted mating or pseudocopulation, pollen is transferred to or from the male head or abdomen. A signal that evolved for insect sexual reproduction has been usurped to become a cue that lures the insect to a flower, a phenomenon called sexual deception. Terms like robbing and deception do not imply psychological intent; they refer to situations where a signalling system that normally increases fitness of both partners has been appropriated such that it only benefits one.

The susceptibility of signalling systems to cheating and deception arises because a common interest can be derailed by an underlying reproductive conflict of interest. From a reproductive viewpoint, the pollinator's interest is in maximising food intake, so if there is an easier way of accessing nectar, such as punching a hole in the Snapdragon pouch, that option may be favoured, irrespective of whether it benefits the flowering plant or not. Similarly, the plant's interest is in pollen transfer, so if there is the possibility of achieving that without the cost of producing nectar, by say manipulating a bee's sexual behaviour, such a strategy may be selected for. Honest signals, where both parties benefit, can only be maintained in the long term if such disruptions are relatively rare. If robbing became too prevalent, Snapdragons would die out because they would no longer be pollinated. Similarly, if sexual deception by bee orchids became too prevalent, the relevant pollinating insect species would die out because males would spend all their time attempting fruitless sex with flowers.

Some of the most complex signalling systems in animals evolved in social insects, where the reproductive conflict of interest is minimal (Bourke 2011). Because of their sterility, the interests of sister workers are, for the most part (Ratnieks et al. 2006), one and the same: to feed and raise the nest's brood. By cheating a sister, a worker would be cheating herself. This has allowed elaborate signalling systems to evolve. Ants and termites can signal to each other through chemical trails (Keller and Gordon 2009), but the most elaborate form of behavioural signalling has evolved in honeybees. Through waggle dances, honeybee workers signal to their sisters the direction and distance of a food source from the nest (von Frisch 1954). If the dance is performed in the 
open, the bee does a waggle run in the direction of the food source. By following the bee, the sisters learn the direction they must travel relative to the sun, with the number of runs indicating the distance. If the dance is performed in the darkness of the nest, the bee orients its waggle run in relation to gravity, and the sisters following the buzzing wings in the dark, translate this into the direction relative to the sun. The basic vocabulary of the waggle dance is similar in all honeybee species (Barth 1991), and phylogenetic and fossil analysis indicates that it originated $>20$ million years ago (Price and Grueter 2015).

The sophistication of honeybee signals for giving instructions contrasts with that found in other animals. Chimps are much smarter than honeybees, yet they have not evolved the ability to give each other directions regarding the whereabouts of food. Chimps do not even point things out on behalf of each other. If a chimp sees some food, then another chimp might follow its gaze and see the food as well, but there is no evidence that the first chimp actively uses its gaze to help the other (Kirchhofer et al. 2012; Tomasello 2006). There are cooperative signals in primates. Vervet Monkeys have three alarm calls: the snake call makes the troop look at the ground, the eagle call makes them dive into the cover of bushes and the leopard call makes them scuttle up to the tree tops (Cheyney and Seyfarth 1990). However, these signals relate to a present danger, rather than the more complex task of providing a set of remote instructions. Dolphins call each other through clicks when circling fish, and whales sing courtship songs; but as far as we know, no non-human animal other than the honeybee gives remote instructions about where something is located (Hauser 2001). The conflict of interest between reproductive individuals seemingly undermines the stable cooperation required to evolve an elaborate vocabulary through natural selection.

Given these findings, how is it that language evolved in humans? Like many other animals, human individuals have a reproductive conflict of interest that may lead them to deceive each other. Yet they exhibit the most elaborate signalling systems known in the animal world. What allowed such a system to arise and be maintained?

An important difference between the languages of humans, compared with honeybees, is that human vocabulary is learned rather than directly established through natural selection. Clues to the origins of human language and intelligence may therefore be found in the mechanisms by which animals learn.

\section{Predictive learning}

Classical conditioning is sometimes described as associative learning, but this is misleading because the timing of the reward is critical. With Pavlov's dog, the salivation response to a bell is only learned if the bell is rung before, not after, the food is given. The dog is therefore learning a cue that predicts the reward, not just a sound that is associated with it. Predictive learning operates retrospectively (Coen 2012; Dayan and Abbott 2005; Hawkins and Blakeslee 2004; Montague 2007). When something unexpectedly good happens to an animal, like getting food out of the blue, dopamine is released, causing excitement. The animal's brain effectively searches back in time to see what might have led to its unexpected good fortune. If a sensory experience, like a bell-ring, is a consistent predictor of good experiences, then the brain rewires so that the experience becomes the source of excitement. The result is that the animal learns cues for rewards. The discrepancy between what it expects and what it experiences effectively poses a problem-how can I predict when this reward will appear again? The animal then learns a cue that helps resolve the problem. Predictive learning has a problem-resolution structure.

One consequence of this process is that the predictive cue can become a substitute reward. After conditioning, it is the bell-ring that triggers dopamine release and excitement in the dog. A new problem is effectively posed to the dog-how can I now predict the bell-ring? It may then learn a cue that predicts the cue, allowing for even earlier anticipation, a phenomenon termed secondary conditioning. After being conditioned to the bell-ring, if a different sound, such as clap of hands, is always made before the bell is rung (even if food does not always follow), the dog will learn to respond to that sound. The dog is effectively learning a chain of events: handclap predicts bell-ring predicts food. Problem-resolution is extended to problem-chain-resolution.

We might say that the dog is unconsciously learning a string of causes, how one thing leads to another. However, the inference of causality is weak. Leaves fall before winter but that does not mean leaf-fall causes winter. A much stronger indicator of causality comes from another form of learning, termed instrumental conditioning.

If a dog paws at you when you are sitting at the table, and you then give it food, the dog will soon learn to always beg in this way. In this case, the dog is not only learning cues (e.g., you sitting at the table) that predict a reward, but what action to take to increase the chance of getting a reward (pawing you). Similarly, a rat may learn to press a lever to obtain food from a dispenser. In these examples of instrumental conditioning, the release of dopamine caused by the reward reinforces behavioural actions that precede it (Dayan and Abbott 2005; Romo and Schultz 1990). Instrumental conditioning is based on the ability of animals to experiment and thus discover, retrospectively, which actions are likely to yield rewards. A discrepancy poses a problemwhat can I do to make this reward appear again? The animal 
then learns an action, or sequence of actions, that helps resolve or reduce the problem by increasing the probability of the reward.

Because the animal can vary its actions, causal relations can be established more firmly with instrumental compared with classical conditioning. After using a remote control for a while to switch on a screen, we begin to sense that pressing the remote makes the screen come on. This is because we can vary the time at which we press, and find that the screen always switches on immediately afterwards. Should the remote then fail to work, we may feel frustrated and press repeatedly, just as a dog who has always been rewarded for begging may paw vigorously if food is denied.

With instrumental conditioning the animal learns a particular action, or sequence of actions, in relation to a reward (or avoiding a punishment). But what if an animal is faced with conflicting courses of action, each of which may yield a reward? How do animals choose?

\section{Choices and neural models}

One of the best-studied cases of how animals choose is in honeybees (Seeley 2010). As the number of honeybee workers in a hive increases in spring, the nest becomes overcrowded. About two-thirds of the occupants may then fly off with the queen to find a new nest, whereas the rest remain behind to rear a new queen. The departing bees do not travel very far, but coalesce to form a swarm that may hang on a tree branch for days, working out where they should site their new nest. It is a critical decision that can determine whether or not the new colony makes it through winter.

During the decision process, scouts are sent out from the swarm to check out options. Each scout explores a potential nest site. When she returns to the swarm she performs a waggle dance. The strength of the dance-the number of dance circuits-conveys the site's quality. If the site has a south-facing entrance, the scout performs more circuits than if it is north-facing, because south-facing helps keep the colony warm. Or if the entrance is high above ground the scout performs more circuits than if it is low down. A higher entrance helps with defence against ground predators. Or if the cavity is large the scout dances more than if it is small, because it allows more honey to be stored. All these aspects of the potential nesting site are summed up in the strength of the scout's dance. The stronger the dance, the more sisters the scout recruits to visit the site she has just come from. The recruits then go to the site to check it out for themselves. If it is a good site, the recruits perform a strong dance when they return to the swarm, recruiting yet more scouts; if it turns out to be a poor site, the recruits perform weaker dances, leading to fewer recruits. That way good sites tend to be visited by more and more scouts, and poor ones by fewer and fewer. Eventually, when a site gets enough visitors, the returning scouts make a high-pitched buzz, signalling to the swarm that they should leave and fly off to the site. The final decision of the swarm does not depend on any single bee telling it what to do. It decides collectively.

Thomas Seeley has compared the way a honeybee swarm makes a decision to the way an individual brain decides (Seeley 2010). In both cases, the decision is based on a population. For the swarm, it is a population of bees; for the brain, a population of neurons. In both cases the populations glean information from their surroundings: scout bees returning from possible nest sites; neurons receive inputs from vision, smell, touch etc. The environmental information is then integrated through a set of rules: for the swarm, it is the way bees signal to each other through dances; for the brain, it is the way neurons trigger and respond to each other through synapses. There is competition between alternative patterns of activity: dances in favour of particular sites, firing of some groups of neurons over others. Eventually one pattern wins, leading to an action: the swarm flies off to its chosen site, the brain causes the animal to act. In both cases, it is a collective decision. You might feel that you as an individual make decisions, but each choice, even the feeling you will get, are the outcome of populations of neurons working together: neural models (Frith 2007).

Unlike the rules for the bee swarm, which are slow to change and have been established over countless generations through natural selection, neural models can be modified within a lifetime through learning. Suppose a dog is faced with the option of begging for food, or running off to chase a ball. If the dog's neural models predict that staying to beg will give a greater reward than playing, it will likely stay. If the dog's expectations are met and it is given tasty scraps from the table, there will be little neural change. But if it turns out that the dog is not given any food, the drop in expectations may lead to a change in synaptic strengths. The dog's neural models become modified so it is less likely to repeat the error-next time it may run off to chase the ball. In this way, through trial and error, neural models can be modified to give improved courses of action.

An animal may learn to make choices with regard to features of its environment such as finding food or avoiding a predator. But for a social animal there is another important feature to be considered: its companions.

\section{Machiavellian intelligence}

A striking feature of primates is that they can learn the reputation of their companions and modify their behaviour accordingly. The psychologist Emil Menzel described an 
experiment in which food was hidden in a chimpanzee enclosure (Menzel 1974). The hiding place was shown to a chimp called Belle, while the rest of her troop was out of sight. Belle was then put back with the others. When all the chimps were released into the enclosure, Belle immediately went to the hiding place and the other chimps followed and shared the food. But as the experiment was repeated, a stronger chimp, Rock, started to keep all the food for himself. So Belle stopped going to where the food was hidden when Rock was around. She would sit on the hiding place instead, covering the food until he left. Rock then started to shove Belle aside when he saw her sitting somewhere for a while, to get the food. So Belle stopped going to where the food was hidden and would sit far away, waiting for Rock to look in the opposite direction before heading for the food. Rock would then start to wander off, only to wheel round to see whether Belle was about to uncover the food. The conflict of interest between Belle and Rock led to an arms race of deception and counterdeception.

Primates also form alliances. Subordinate male baboons may take it in turns to threaten and distract the alpha male, whereas the other copulates with a female (Hausfater 1975; Packer 1977). By forming an alliance they have usurped a signal normally used for threat display for their own benefit. Primates spend an inordinate amount of time grooming each other, exchanging favours and forming alliances that might come in useful later (Dunbar 2004).

Observations such as these have led to the suggestion that the main driver for increase in brain size and intelligence in primates was the need to deal with the complexity of social interactions (Byrne 1995; Humphrey 1976; Whiten and Byrne 1997). According to this Machiavellian intelligence hypothesis, learning to navigate deceptions, reputations and alliances among members of the same group played a greater part in shaping primate intelligence than dealing with challenges such as making tools. Primates sharpened their minds on each other, not stones. Support for this hypothesis comes from the observation that the extent of tactical deception in primate species correlates with the relative size of the neocortex (Byrne 1995).

It remains unclear, however, how the Machiavellian intelligence hypothesis could account for human intelligence, which far exceeds that of other primates. Humans have a much greater ability, for example, to understand others' beliefs (theory of mind) than any other primate (Hall and Brosnan 2017). It is generally assumed that language was key to the rise in human intelligence, but how human language arose and why it was developed to such an extraordinary degree is a matter of debate (Fitch 2010). Some clues may be found from how animals might share what they have learned.

\section{The storytelling arms race}

What an animal learns is normally trapped within the individual. After a dog learns that a bell-ring predicts food, the dog is unable to convey this knowledge to another dog. The most direct way of achieving this would be for the dog to get the other dog to go through the same experiences it went through. However, it is not easy for an animal to recreate what happened to it on behalf of another. An alternative would be to repeat experiences indirectly, in a compressed or symbolic form. This is what happens with a honeybee's waggle dance. By following the dancer, the sisters are taken on a simulated flight path. Over many generations, natural selection has honed the dance and its response so that honeybee brains convert the simulation into an actual flight path. It needs great social stability and cooperation for a system like that to evolve. Moreover, because each 'word' in the waggle routine has been crafted by natural selection, the system is very slow to change.

Human language provides another way of sharing knowledge. Like honeybees, humans use simulations to share what they have learned, but create them more flexibly: they tell stories (Cron 2012; Gottschall 2012; Haven 2007). They create simulated problems, followed by a simulated chain of events, with one problem leading to the next, ending in a resolution. Problem-chain-resolution. Each element can be varied, allowing for an enormous number of possibilities. I shall refer to this problem-chain-resolution structure used to share knowledge as a story. It is no accident that this structure mirrors the way animals learn: stories work by tapping into our neural learning mechanisms.

It is natural to think that telling stories came after language and intelligence. It would seem you need high intelligence and an elaborate language before you can tell stories. But that assumes stories of early humans were as sophisticated as those of today; like assuming primitive wings were as elaborate as the most aerodynamic ones of modern birds. Storytelling, however, may not have come fully fledged.

At some point, through the need to negotiate social interactions, primate intelligence may have reached the point where problems and resolutions could be shared through grunts and gestures: Predator coming, follow me. This problem-resolution phrase, or proto-story as I shall call it, uses language to engage the listener with a discrepancy or problem (predator coming) and a suggested action to resolve it (follow me). Perhaps, such signals were initially established among close relatives (e.g., mother and child), where kin selection favours honest communication (Fitch 2010). But as soon as honest signalling arose, so did the potential for dishonest signalling. A male wants to have sex but the female is not keen, so he grunts: Predator 
coming, follow me. If deceit of this sort had become too prevalent, human language might have been stopped in its tracks. However, just as intelligence could be used to deceive, so it could be used to detect deceit. Along with the ability to tell proto-stories may have come the ability to detect lies. The importance of being able to detect cheaters for the evolution of human intelligence has been emphasised by others (Cosmides et al. 2010). Here I wish to highlight the role of detecting cheaters through what they say.

Apart from body language, there are two basic ways in which we can tell whether someone is lying. One is through empirical contradiction, where evidence speaks against the claim being made. If, after the male says predator coming, follow me, the female stays and observes no predator, she may feel the male deceived her, and trust him less in the future. Moreover, if she is able to share her discovery with the social group through gossip (Dunbar 2004), the male may acquire a reputation as being untrustworthy and be excluded from social transactions, bringing a further cost to his lie.

Another way of detecting lies is through selfcontradiction. Suppose a male asks another for help, and says he will help him in return later. If, after getting help, the male says he will not return the favour, the second male may feel he has been deceived. The contradiction here is logical rather than empirical, as the individual has contradicted what he himself said.

Basic empirical or self-contradictions may have been used to detect lies as proto-stories arose. More intelligent individuals, who were better at spotting contradictions, would have been at an evolutionary advantage as they would be less readily duped. The better they were at detecting lies, the better they would have also been at preventing any of their own lies from being spotted and thus at manipulating others. The standards of lying and storytelling would then increase, driving the need to be even more intelligent and linguistically able to stay ahead. Machiavellian intelligence would be operating at a new level, not just on behaviours, but on what was being said. Building on the neural mechanisms that allow predictive chains of events to be learned, the basic problem-resolution structure may have been expanded to problem-chain-resolution, to give fuller stories that were more engaging, informative and convincing. With more elaborate honest stories, also came more elaborate dishonest ones, requiring even higher intelligence and better reasoning to detect contradictions and lies. Lies may have been kept rarer than truths, but the frequency of communication would mean that they could still have been common. Spotting contradictions may have become a reward in itself, perhaps ushering in the telling of comedies or jokes, harmless deceptions that give pleasure when errors or contradictions are revealed (Miller 1988).
With greater intelligence and language abilities also came improved abilities to cooperate and tackle practical problems like hunting or making tools, increasing the success of the problem-solvers.

Thus, starting with sufficient intelligence to express proto-stories and detect basic contradictions, our human ancestors may have embarked on a runaway process that spurred language and intelligence to ever greater heights, through the storytelling arms race between truth and deception. The notion of an evolutionary arms race, or runaway selection, underlying the rise of human intelligence has been proposed before with regard to sexual selection (Miller 2001) or competition between groups (Alexander 1990). The arms race I am proposing is based on the inherent tension between honesty and deception in storytelling itself.

This process depends on a balance between trust and distrust. With blind trust, liars get away with murder; with blind distrust there is no reason to communicate; but with each held in check through the storytelling arms race, intelligence grows. The two-headed nature of stories, the ability to inform or deceive, may have been a key driver for the evolution of human intelligence. An attractive feature of this explanation is that it accounts for why increased intelligence (reasoning) was intimately linked with increased language skills (storytelling).

\section{Stories we tell ourselves}

Along with the ability of humans to share stories with each other, would have come the ability to share them with themselves. They could dispense with the external audience and become character, narrator and listener all in one. It is $m e$ who is facing this problem, $m e$ who is free to decide, $m e$ who is trying to do their best, they who are the enemy trying to stop me, or friends by my side. Humans began to use stories to analyse their own actions, to think through their problems consciously and plan ahead, to give meaning to their lives. They might start with an internal discrepancy, like something did not feel right. Or perhaps they were trying to decide upon an action, like which partner to choose. They could then embark on an internal dialogue, explore alternative hypotheses, follow likely chains of reasoning to help them decide. They listened to their own story as they told it to themselves, and modified their own neural models, their sense of understanding. Telling themselves stories became an inseparable part of their intelligence, of conscious understanding.

The two-headed nature of stories would also have begun to apply to the stories humans told themselves (Barnes 1994). If they found themselves acting in a way that they would condemn in others-stealing from a trusted friend, or lying about 
an infidelity - their neural models might battle with each other, causing them distress. To reduce such cognitive dissonance, they might tell themselves stories to justify their actions-their friend would have done the same to them, everyone lies after all (Festinger 1957; Travis and Aronson 2013). They could clothe themselves with stories to prevent them seeing what they least wished to see. Self-deception may also have been selected for to improve the ability to get away with lies, by reducing the chance of a liar accidentally releasing cues of dishonesty to receivers (Trivers 2013).

With the advent of storytelling also came the possibility of it getting out of control. If dopamine is more active than normal in the brain, the balance of neural rewiring can be upset (Previc 2009). Discrepancies can be given undue weight, and beliefs may become detached from reality (Fletcher and Frith 2009). Genes that give higher risk of schizophrenia may act by modulating the number of synapses and their sensitivity to neurotransmitters like dopamine, so rewiring may happen when it should not (Sekar et al. 2016). Mistaken neural models can then get reinforced through internal storytelling, further confirming and justifying suspicions. If others do not believe your stories, you stop trusting them, reinforcing your convictions, causing further distress and isolation. When storytelling goes wrong so does our intelligence.

How did storytelling lead to further developments, such as fiction, science and mathematics?

\section{Fiction}

A stranger seems friendly, so you invite them into your home. You fetch him a drink, but while you are away he steals something. You tell that story in the first person-I thought the stranger was friendly but he turned out to be a thief. Your listener shares the story-did you hear how she was fooled by a thief who pretended to be friendly? It becomes a story about others. If the story carries a valuable lesson, it may continue to get passed on. To make the story even more effective, we might elaborate and make the discrepancies stronger. We turn the stranger into a cunning wolf, and instead of stealing, they eat you up. Fiction gives you the freedom to suppose, to make discrepancies more striking, the causal chains more engaging. This ability to suppose, or envisage alternative possibilities, may also derive from deception. By giving voice to lies we create imagined alternatives. And by suspecting lies we imagine alternative versions of events. Fiction builds on these primal skills not to create lies, for we understand not to take the story literally, but imagined worlds from which we may learn and be entertained.

According to the dramatist Lajos Egri, 'In a play, each conflict causes the one after it. Each is more intense than the one before. The play moves, propelled by the conflict created by the characters in their desire to reach their goal: the proof of the premise', (Egri 1942). The premise is the key idea or message that the story tries to demonstrate. Egri gives the premise of Romeo and Juliet as Great love defies even death, or Macbeth as Ruthless ambition leads to its own destruction. A story without a premise is like a journey without purpose.

Contradiction and deception played a key role in the earliest stories we know of. In the Sumerian Epic of Gilgamesh, which goes back $>4000$ years, the hero, Gilgamesh, beats his adversary Humbaba in a fight. Before the fight, Humbaba had said he wanted to rip out Gilgamesh's throat, but after being vanquished he contradicts himself, saying he just wants to be Gilgamesh's servant. Gilgamesh decides not to trust him and cuts off his head. In another scene, Gilgamesh lies about having dosed off for a short time, but is caught out by the evidence that freshly cooked loaves have gone mouldy while he was asleep.

Take all deception out of a story, with everyone being completely open and honest, and much of the drama is gone. Situations of conflict, where characters have to choose whether to act according to one value or another, are most revealing because they put our neural models to the test (Foster-Harris 1959). Should we be guided by ambition or friendship, love or life, duty or desire? Our learning mirrors the learning a story's characters go through as they encounter opposition-mortality, an evil uncle, a jealous lover, their own weaknesses. They realise the futility of seeking ever-lasting life, the need to take action over theorising, the meaning of true love. It is as though the characters have a brain with neural models that get modified by what they experience. And by following their story, we are taken along a parallel journey. Our neural models end up modified too. Good stories make us wiser. They help us construct our world.

Fiction can convey truths through imaginary chains of events, seemingly the opposite of science that concerns itself with worldly observations. What is the relationship between science and storytelling?

\section{Science}

According to J.B.S. Haldane, one of the founding members of the Genetics Society, 'Modern science began with great acts of doubt. Copernicus doubted that the sun went round the earth, Galileo that heavy bodies will fall faster than light ones, Harvey that the blood flowed into the tissues through the veins. They each had a theory to replace the old one, and their observations and experiments were largely designed to support that theory. But as time went on these theories, too, were found wanting. The planets do not go round the sun in 
circles as Copernicus thought; gravity is a more complex affair than Galileo or even Newton believed' (Haldane 1930).

Science began with doubting stories told about how the world works. And the way scientists tested these doubts, distinguished truth from falsity, was to look for contradictions. Someone says the earth is flat; another says life can spontaneously generate from old rags. Should you believe them? No! Look for evidence. Make observations. Set up controlled experiments. Check reasoning for selfconsistency. Nature itself cannot be wrong, but what we say about it can. And if a contradiction is found, then seek better explanations, stories that do hold up, even if they seem counter-intuitive at first sight. There is no implication here that the proponent of a false hypothesis intends to deceive. They may be giving the best explanation as far as they know. But the tools the scientist uses to test the hypothesis, by seeking empirical or logical contradictions, are the very same as those used to detect lies.

If humans had been as honest as honeybees, with no drive to deceive, there would have been no need to doubt, just accept. But humans are storytelling animals (Gottschall 2012). Through stories they honed their skills in causal reasoning and finding empirical contradictions, in trying to tell whether someone was speaking the truth or not. Science became possible when those same skills were applied to stories about the natural world. Scientists' cares about truth and falsity were built on cares established through the storytelling arms race. Gilgamesh came before the theory of gravity.

How do we know that causal reasoning about the world did not first develop with practical purposes in mind, such as making tools or dealing with material challenges? The causal explanations of early civilisations were imbued with purpose. This terrible storm has happened because the gods are angry. I'm ill because of a curse. This stone falls because it wants to be nearer the ground. Agents with motives caused things to happen. Such explanations make little sense if causal reasoning first evolved to deal with the inanimate, but they are natural if it arose as a way of deciphering the motives of others. Our ancestors looked for motives in the sky because they had honed their causal reasoning on each other, where emotions and actions drive events. They could still apply their intelligence to the material world, to develop better tools or hunting methods, but a driving force for much of their intelligence came from deciphering the words and actions of others, so that they knew who and what to trust. Causal reasoning was only depersonalised much later, as science became established.

Storytelling not only provided some of the basic skills and cares for doing science; it also provided the mechanism for scientists to share knowledge. The basic story format of problem-chain-resolution is also the way scientists communicate through papers and presentations. A paper starts with a problem: a previous hypothesis is unsatisfactory, a question remains unanswered, some knowledge in a particular area is lacking. It then attempts to resolve the problem through a chain of demonstration, with each problem leading reasonably to the next.

Some scientific papers are largely theoretical, exploring the consequences of hypotheses without presenting novel experimental data. Others have experiments and results following each other in a chain: we did an experiment that gave this result, so based on that, we did another experiment that gave the following result, and so on; like actions and consequences following each other in a drama. But whatever the type of paper, it needs to have a problem together with a chain of demonstration that tries to resolve it. Without any sort of problem, the reader will wonder why they should bother with the paper, and without a reasonable chain, the reader would not believe or understand what they were being told.

A scientific paper ends with a resolution or conclusion. Resolution does not necessarily mean answering the question or problem posed. It may be that the results are inconclusive with regard to a hypothesis. Resolution in a scientific paper means a balanced evaluation of the possible explanations and results. Scientific communication follows the problem-chain-resolution story format because it is built on the way we and other animals learn. A good scientific paper improves understanding, our neural models of the world.

Every scientific discovery is woven into two types of story (Alon 2009). There is the story of how the discovery was made: conflicts, meandering paths, moments of insight, outdoing competitors. How you tell that story may depend on where you stand. Then there is the story about how the discovery is shared with others. Here, the scientist tries to avoid individual prejudice and focuses on getting the scientific message across. It still follows a storytelling structure, but subjective feelings are excluded as far as possible.

According to the view presented here, science was born when skills that were first developed to detect empirical and self-contradictions in stories, were turned upon our sayings about the world so as to get closer to the truth. Scientists then shared their knowledge, gained by experiment, reasoning and observations, through their own stories, couched in their particular style and terms. By continually checking each other's claims through first-hand observation, dishonesty was kept low and scientists put forward hypotheses that reflected the best of their knowledge (though they could still be wrong). This culture of honest investigation and exchange, with an ultimate arbiter, Nature, that cannot lie, allowed science to make rapid progress. Scientific knowledge could also be used for practical benefit, through development and exchange of technological stories. 
What about mathematics? Mathematical results need have no reference to empirical findings, so where did our ability and drive to do mathematics come from?

\section{Mathematics}

The writer, Austin Freeman, described what he called inverted mysteries: 'In the conventional detective story the interest is made to focus on the question, 'Who did it?' The identity of the criminal is a secret that is jealously guarded up to the very end of the book, and its disclosure forms the final climax... Would it be possible to write a detective story in which from the outset the reader was taken entirely into the author's confidence, was made an actual witness of the crime and furnished with every fact that could possibly be used in its detection?' (Freeman 2001). With an inverted mystery, you are first given the answer, the murderer. Then you are shown how the detective arrives at that answer through a series of reasoned and evidential steps: the proof. Freeman wrote several stories along these lines (the Dr Thorndyke mysteries), as did writers before him, such as Dostoyevsky with Crime and Punishment, and after him, as in writers of the television series Columbo (whose main character was inspired by the detective from Crime and Punishment, (Levinson and Link 1981)).

Mathematical demonstrations follow a similar structure to inverted mysteries-answer before proof. Consider Euclid's proof of the infinity of prime numbers.

Theorem: there are infinitely many prime numbers.

Proof: suppose the contrary, that there are a finite number of primes. The series of prime numbers must then end with a final largest prime number. Call it $L$. Suppose we multiply all of the prime numbers together and then add 1 . Call this larger number $P=(2 \times 3 \times 5 \times 7 \times 11 \ldots \times L)+1$. Is $P$ prime or non-prime? If we divide $P$ by the first prime number, 2, we get a remainder of 1 , because 2 goes into $(2 \times 3 \times 5 \times 7 \times 11 \ldots \times L)$. If we divide $P$ by the second prime number, 3 , we also get a remainder of 1 . The same applies if we divided $P$ by any of the other prime numbers. That means $P$ cannot be divided by any prime number without leaving a remainder (unless the prime number is larger than $L$, which would contradict the assertion that $L$ is the largest prime number). Given that all non-prime numbers are divisible by prime numbers, it follows that $P$ cannot be a non-prime number. The only possibility left is that $P$ is a prime number. But this contradicts the claim that $L$ is the largest prime number, because $P$ is bigger than $L$. Thus, the original assumption that there are a finite number of primes cannot be true-there must be infinitely many.

With a mathematical proof you are first given the answer: the theorem. The problem is to figure out how the theorem can be demonstrated. The proof is a chain of reasoning that inevitably leads you there-problem-chain-resolution. Each link in the chain has to follow logically from the previous one, or the proof is flawed. Both fiction and mathematics begin with supposing. Suppose a nephew learns his uncle killed his father, suppose some lovers are trapped on a sinking ship, suppose there is a finite number of primes, suppose certain axioms hold true. But instead of a causal chain of actions, the mathematician is presented with a series of logical operations. The demonstration ends with a resolution-the theorem is proved.

Proofs allow mathematicians to share understanding. Understanding a proof does not simply mean checking each logical step; it involves exploring its ramifications; knowing why each step is important and whether other steps might have been taken (Krantz 2011); just as understanding a drama is not just about following the plot, but empathising with characters and seeing how their behaviour follows from their personalities and experiences. And once a proof has been understood, a mathematician can use similar reasoning to help him or her prove other theorems. A good proof is one that makes us wiser (Manin 1998). Mathematicians share what they have learned through stories; it is just that they are written in a highly abstract, condensed way.

Just as science may have arisen from the ability to detect lies through empirical contradictions, mathematics may originate from the drive to spot lies through selfcontradictions. There are no self-contradictions in the natural world. A mountain cannot be inconsistent with itself. But what humans say can be self-contradictory. And one reason for humans contradicting themselves is because they are lying, covering something up, and inadvertently let slip.

As humans honed their powers of reasoning to detect lies through self-contradiction, they found they could apply those powers in a more abstract way to mathematics. Say there is a finite number of primes. Follow the logical consequences and we end up with a contradiction. So there cannot be a finite number of primes after all. It is as though the claim of finiteness is shown to be a lie. Except there was no intent to deceive. The claim was put forward to help demonstrate the proof, as part of the story. Not all mathematical proofs depend on demonstrating a contradiction, but they all depend on logical reasoning, on ensuring selfconsistency, that everything adds up.

It is as though humans developed a remarkable storytelling lie detector and then found they could use it to arrive at other truths, the stories of science and mathematics; just as eyeglasses were first developed to improve sight, and later it was found they could be turned towards the stars.

Although the ability to reason may have evolved as a way of dealing with deception, it seems that this neural ability is separable to some extent from its domain of application (social or non-social). People with autism can 
reason effectively but are less able to apply reasoning to social situations, such as detecting when someone is lying, or telling a joke (Baron-Cohen 2007). Also, a brilliant scientist may be a very poor politician.

\section{Cultural evolution}

Biologically there is little to distinguish the brains we are born with, from those of our Stone Age ancestors living 10 thousand years ago (Harari 2015). But over the years that have separated us, storytelling has become more and more sophisticated and far-reaching through cultural evolution and the technologies it has fostered. By being able to pass on and share stories more widely, through writing, travel, printing and the internet, storytelling has ramified into every part of our life. Our actions, fears and joys are explored through dramatic stories. Happenings, past and present, are conveyed through histories and news stories (McKane 2006). Justice is dealt with through stories told to judges and juries. The workings and dealings with the world through scientific and technological stories. In each case, stories have been enriched by building on what went before. Yet the two-headed nature of storytelling also brings its dark side. Amid its many remarkable successes during the last hundred years, genetics has witnessed horrific abuse and distortion of its findings, from persecutions in the wake of Lysenko's denial of Mendelian genetics (Ings 2016; Pringle 2009), to Nazi eugenic policies (Kelves 1995). The deceitful head of storytelling is never far.

Through stories, human intelligence has become a collective intelligence, in which ideas and information can be shared with others with unprecedented speeds and reach. It is an intelligence that operates not only in the present but also reaches into the future and past, because, like DNA, stories can be passed on from one generation to the next.

\section{Conclusion}

I have suggested that a major contributing factor to the evolution of human language and intelligence was an arms race between truth and deception in storytelling, a process that was also critical for establishing the abilities and cares to do science and mathematics.

The arms race can be traced to a tension between the benefits and conflicts of interests in signalling. In social insects like honeybees, an elaborate language between workers could evolve because the conflict of interest was reduced through sterility. For humans, however, the conflict of interest became a spur for increasing linguistic complexity and intelligence.
Through the drive to deal with complex social alliances and reputations, primate intelligence may have reached the point where knowledge could be shared through problem-resolution proto-stories. The structure of these proto-stories was built on the way animals learn through discrepancies and finding actions that reduce them. As soon as honest proto-stories became possible, so did dishonest ones. Individuals with greater intelligence and language skills would be better at detecting lies through empirical or self-contradictions, and better at avoiding contradictions themselves and so using their own proto-stories to manipulate others, giving them a reproductive advantage. Selection for increased intelligence in turn led to more elaborate stories, bringing in the problem-chain-resolution structure, built on how neural models are improved through learning. A key feature of this explanation is that the drive for increased intelligence (reasoning) and language skills (storytelling) were intimately linked.

As stories became more complex, they led to more elaborate forms of deception, and greater skills in detecting falsehoods through searching for contradictions, spurring the storytelling arms race further on. A balance between trust and distrust was essential: too much trust would allow lies to go unchallenged; too much distrust would lead to paranoia and a breakdown in communication; but with each held in check through the storytelling arms race, intelligence could grow.

In developing their storytelling skills on others, humans also told them to themselves, allowing them to plan ahead, and think problems through consciously. Through fictions they could share their understanding more effectively by making discrepancies stronger and more engaging. Greater intelligence also enabled humans to tackle practical problems with more success.

As stories could be passed on from one generation to the next, so they became subject to cultural evolution. Science arose when skills in detecting lies through contradictions were applied to stories about how the world operates. By doubting these stories, and testing them through observations, reasoning and experiment, scientists could come up with better explanations. They could then share their findings through their own stories, based on the problem-chain-resolution structure, allowing further critical evaluation and advances to be made. Mathematics arose when skills in detecting lies through logical or selfcontradictions were applied to more abstract reasoning, and shared through their own form of story. The advances in science and mathematics also provided powerful ways of tackling practical problems, leading to improved technologies and means of communication.

We have now reached the point where stories can be exchanged and spread with unprecedented speed and reach. 
This brings many benefits, but also dangers, for lies may spread as well as truths. People may be tempted to tune only into the stories that confirm their beliefs, dismiss contradictory evidence as fake news, accept lying as a norm. And because much of the evidence being evaluated is provided indirectly through messaging or the internet, the potential for manipulation is high. Just as the stories we tell ourselves can get out of control, so can those of our collective intelligence. It may seem the answer lies in pointing to facts rather than stories; that facts speak for themselves. But we are storytelling animals. Facts only speak through the stories we tell. The challenge for the future will be to ensure that stories based on the values of honesty, doubt, evidence, reason and fair-mindedness, which lie at the heart of science, are more powerful and effective than those based on deception.

Acknowledgements We thank Kirsten Bomblies, Andrew Bourke, Chris Frith, Alain Goriely, Martin Howard, Mark Miodownik and Przemyslaw Prusinkiewicz for critical reading and helpful comments on the manuscript.

\section{Compliance with ethical standards}

Conflict of interest The author declares that he has no conflict of interest.

Publisher's note: Springer Nature remains neutral with regard to jurisdictional claims in published maps and institutional affiliations.

\section{References}

Alexander RD (1990) How did humans evolve? Reflections on the uniquely unique species (Museum of Zoology (Special Publication No. 1).), pp. 1-38

Alon U (2009) How to choose a good scientific problem. Mol Cell $35: 726-728$

Ayasse M, Schiestl FP, Paulus HF, Ibarra F, Francke W (2003) Pollinator attraction in a sexually deceptive orchid by means of unconventional chemicals. Proc Biol Sci 270:517-522

Barnes JA (1994) A pack of lies: towards a sociology of lying. Cambridge University Press, Cambridge, UK

Baron-Cohen S (2007) I cannot tell a lie. Character 3:52-59

Barth FG (1991) Insects and flowers: the biology of a partnership. Princeton University Press, Princeton, New Jersey

Blumenschine RJ, Cavallo JA (1992) Scavenging and human evolution. Sci Am 267:90-96

Bourke AFG (2011) Principles of social evolution. Oxford University Press, Oxford

Byrne R (1995) The thinking ape: evolutionary origins of intelligence. Oxford University Press, Oxford

Cheyney DL, Seyfarth RM (1990) How monkeys see the world: inside the mind of another species. University of Chicago Press, Chicago

Coen E (2012) Cells to civilizations. Princeton University Press, Princeton

Cosmides L, Barrett HC and Tooby J (2010) Colloquium paper: adaptive specializations, social exchange, and the evolution of human intelligence. Proc Natl Acad Sci USA 107:9007-14
Cosmides L, Tooby J (2013) Evolutionary psychology: new perspectives on cognition and motivation. Annu Rev Psychol 64:201-229

Cron L (2012) Wired for story: the Writer's guide to using brain science to hook readers from the very first sentence. Ten Speed Press, Berkeley

Dayan P and Abbott LF (2005) Theoretical neuroscience: computational and mathematical modeling of neural systems (MIT Press, Cambridge, MA, USA)

Dunbar R (2004) Grooming, gossip and the evolution of languate, 2nd edn. Faber and Faber Ltd., London

Egri L (1942) The art of dramatic writing: its basis in the creative interpretation of human motives (original title: how to write a play). Simon \& Schuster, New York, NY

Festinger L (1957) A theory of cognitive dissonance (Stanford: Stanford University Press)

Fitch WT (2010) The evolution of language. Cambridge University Press, Cambridge

Fletcher PC, Frith CD (2009) Perceiving is believing: a Bayesian approach to explaining the positive symptoms of schizophrenia. Nat Rev Neurosci 10:48-58

Flinn MV, Geary DC, Ward CV (2005) Ecological dominance, social competition, and coalitionary arms races: Why humans evolved extraordinary intelligence. Evol Hum Vol Behav 26:10-46

Foster-Harris (1959) The basic patterns of plot. University of Oklahoma Press, Norman

Freeman RA (2001) The singing bone. House of Stratus, London

Frith C (2007) Making up the Mind (Blackwell, Oxford)

Gibson KR, Ingold T (eds.) (1993) Tools, language, and cognition in human evolution. Cambridge University Press, Cambridge UK

Gottschall J (2012) The storytellling animal: how stories make us human. Houghton Mifflin Harcourt, Boston, New York, NY

Haldane JBS (1930) The duty of doubt. In possible worlds and other essays. Chatto and Windus, London

Hall K, Brosnan SF (2017) Cooperation and deception in primates. Infant Behav Dev 48:38-44

Harari YN (2015) Sapiens: a brief history of humankind. Vintage, London

Hauser M (2001) Wild minds: what animals really think. Penguin Books, London

Hausfater G (1975) Dominance and reproduction in baboons (Papio cynocephalus). S. Karger, Basel

Haven K (2007) Story proof: the science behind the startling power of story. Connecticut: libraries Unlimited, Westport

Hawkins J, Blakeslee S (2004) OnIntelligence. Henry Holt, New York, NY

Hill K (1982) Hunting and human evolution. J Human Evol 11:521-544

Humphrey NK (1976) The social function of intellect. In: Bateson PPG, Hinde RA (eds.) Growing points in ethology. Cambridge University Press, Cambridge, pp. 303-317

Ings $S$ (2016) Stalin and the scientists: a history of triumph and tradegy 1905-1953. Faber \& Faber, London

Inouye DW (1983) The ecology of nectar robbing. In: Bentley B, Elias T (eds.) The Biology of Nectaries. Columbia University Press, New York, NY

Kaplan H, Hill K, Lancaster J, Hurtado AM (2000) A theory of human life history evolution: diet, intelligence, and longevity. Evol Anthropol 9:156-185

Kaplan HS and Robson AJ (2002) The emergence of humans: the coevolution of intelligence and longevity with intergenerational transfers. Proc Natl Acad USA 99, 10221-10226

Katz Y (2013) Against storytelling of scientific results. Nat Methods 10:1045

Keller L, Gordon E (2009) The Lives of Ants. Oxford University Press, Oxford 
Kelves DJ (1995) In the name of eugenics: genetics and the uses of human heredity. Harvard University Press, Cambridge MA

Kirchhofer KC, Zimmermann F, Kaminski J, Tomasello M (2012) Dogs (Canis familiaris), but not chimpanzees (Pan troglodytes), understand imperative pointing PLoS ONE 7:e30913

Ko KH (2016) Origins of human intelligence: the chain of tool-making and brain evolution. Anthropol Noteb 22:5-22

Krantz SG (2011) The proof is in the pudding: the changing nature of mathematical proof. Springer, New York, NY

Levinson R, Link W (1981) Stay tuned: an inside look at the making of prime-time television. Ace Books, New York, NY

Magee B (2010) Popper (Fontana Press)

Manin YI (1998) The Berlin Intelligencer: good proofs are proofs that make us wiser. Paper presented at: International Congress of Mathematicians. Springer-Verlag, Berlin

McKane A (2006) Newswriting. SAGE, London

Menzel EW (1974) A group of chimpanzees in a 1-acre field: leadership and communication. In: Shrier AM, Stollnitz F, (eds.) Behaviour in nonhuman primates. Academic Press, New York, NY, pp 83-153

Miller GF (2001) The mating mind: how sexual choice shaped the evolution of human nature. Vintage, London, UK

Miller J (1988) Laughing matters: a serious look at humour (Longman)

Montague R (2007) Your brain is (Almost) perfect: how we make decisions. Plume, New York, NY

Packer C (1977) Reciprocal altruism in Papio anubis. Nature 265:441-443

Popper K (2002) The Logic of Scientific Discovery, 2nd edn. (Routledge)

Potts R (1998) Variability selection in hominid evolution. Evolut Anthropol 7:81-96

Previc FH (2009) The dopaminergic mind in human evolution and history. Cambridge University Press, Cambridge, UK

Price RL and Grueter C (2015) Why, when and where did honey bee dance communication evolve? Front Ecol Evol 5: https://doi.org/ $10.3389 /$ fevo. 2015.00125
Pringle P (2009) The murder of Nikolai Vavilov: the story of Stalin's persecution of one of the great scientists of the 20th century. JR Books Ltd., London

Ratnieks FL, Foster KR, Wenseleers T (2006) Conflict resolution in insect societies. Annu Rev Entomol 51:581-608

Romo R, Schultz W (1990) Dopamine neurons of the monkey midbrain: contingencies of responses to active touch during selfinitiated arm movements. J Neurophysiol 63:592-606

Rozsa L (2008) The rise of non-adaptive intelligence in humans under pathogen pressure. Med Hypotheses 70:685-690

Seeley TD (2010) Honeybee democracy. Princeton University Press, Princeton, New Jersey

Sekar A, Bialas AR, de Rivera H, Davis A, Hammond TR, Kamitaki N, Tooley K, Presumey J, Baum M, Van Doren V, et al. (2016) Schizophrenia risk from complex variation of complement component 4. Nature 530:177-183

Smith JM, Harper D (2003) Animal signals. Oxfird University Press, Oxford

Tomasello M (2006) Why don't apes point. In: Enfield NJ, Levinson SC (eds.) Roots of Human Sociality: Culture, cognition and interaction. Berg, Oxford \& New York, NY, pp 506-524

Travis C, Aronson E (2013) Mistakes were made (but not by me): why we justify foolish beliefs, bad decisions and hurtful acts. Pinter \& Martin Ltd., London

Trivers R (2013) Deceit and self-deception: fooling yourself the better to fool others. Penguin, London, UK

von Frisch K (1954) The dancing bees. Methuen \& Co, London

Whiten A, Byrne RW (eds.) (1997) Machiavellian intelligence II: extensions and evalutations. Cambridge University Press, Cambridge

Wrangham RW, Jones JH, Laden G, Pilbeam D, Conklin-Brittain N (1999) The raw and the stolen. Cooking and the ecology of human origins. Curr Anthropol 40:567-594

Wynn T (1988) Tools and the evolution of human intelligence. In: Byrne RW, Whiten A (eds.) Machiavellian intelligence. Oxford University Press, Oxford, pp. 271-284 